\title{
Examining technology transfer activities at universities: Does one recipe explain all outcomes?
}

\author{
Berbegal-Mirabent, Jasmina ${ }^{\text {; }}$ Guerrero, Adrián ${ }^{\text {a }}$ \\ ${ }^{a}$ Department of Economy and Business Organisation, Universitat Internacional de \\ Catalunya, Spain.
}

\begin{abstract}
The growing importance knowledge and innovation are acquiring as the basis for economic development and growth has lead universities to expand their traditional functions, spreading their commitment in the contribution to economic and social welfare through their so-called third mission.

Certainly, universities have turned into one of the most important engines for regional development, therefore, they are called to play a paramount role in the provision of new knowledge, which is expected to have a positive impact in the innovation systems of their neighbouring regions. However, these new demands are not followed by a larger availability of resources. On the contrary, universities are struggling to simultaneously carry out teaching and research activities alongside with technology transfer ones.

In this study we aim at scrutinize which are the determinants of technology transfer outcomes at universities. By means of an empirical analysis, we examine which combination of resources lead to higher technology transfer outcomes when these take the form of patents, spin-offs and $R \& D$ contracts. Data from the Spanish higher education system for the period 2004-2011 is used. Implications for policy and practice are discussed.
\end{abstract}

Keywords: technology transfer; universities; third mission; spin-offs; patents; $R \& D$ contracts. 


\section{Introduction}

Over the last decades, research activities have expanded and new figures have appeared professionalising different tasks related with research activities (Berbegal-Mirabent et al., 2013). In this context, universities are seen as institutions that generate knowledge and transmit it to people. The contemporary university is a combination of teaching, research, entrepreneurial and scholastic interests. Universities do not only provide highly qualified graduates and researchers, but they also offer innovative solutions through technologytransfer mechanisms that foster links with the local industry system. This means that, despite teaching and research are key actions for satisfying society's knowledge demands, it is in the local development where this process articulates. This situation not only requires a high standing university able to educate people with the latest technologies, but also a capable university to translate research results into marketable outcomes.

The growing awareness of how universities can contribute to regional development has lead governments to rethink how to maximize the benefits arising from universities. Collaboration with businesses, local and regional public authorities and other local actors are the traditional practices to reach this purpose, however, benefits arising from these relationships are still far from their true potential, and strongly differ from one university to another (Shattock, 2009).

To cope with these requirements for a major collaboration with firms, universities have enlarged their service portfolios and introduced significant changes in their traditional ways of operating. However, universities face with important constraints in terms of resources, which impede them to successfully engage in different forms of technology transfer activities while maintaining high levels in teaching and research duties. This translates into saying that universities are struggling to survive in a competitive environment where they are constantly asked to simultaneously excel at multiple tasks.

Recognizing this limitation, the original contribution of this study relies in assessing the antecedent conditions of specific technology transfer outcomes, but also in examining a new model, where the desired outcome is a technology transfer output whatever being its form (patent, spin-off or R\&D contract). Because resources are scarce and universities might address their objective function differently, not all universities should allocate their efforts in producing the same technology transfer outcomes. The empirical application considers the Spanish higher education system for the period 2004-2011. Using qualitative comparative analysis, we test if there is a unique formula that leads to the desired outcomes. 


\section{Technology transfer activities}

Both academics and policy makers are interested in how universities can develop their third stream function to become more adept at exploiting their knowledge-base and transfer it to the private sector (Lockett \& Wright, 2005). Third mission denotes activities primarily designed to support regional engagement and regional economic growth more generally (Shattock, 2009). This mission allows universities to stimulate knowledge creation, knowledge flows and its valorisation and commercialisation into the marketplace. The convergence of three main axes (entrepreneurship, innovation and social commitment) has helped universities respond to the social pressures they face.

Two main ways are primarily envisioned when talking about third mission activities (Berbegal-Mirabent et al., 2013): placing products and services in the marketplace directly (through the creation of spin-offs) or indirectly (by interacting with firms). University spinoffs can be defined in terms of the identification and exploitation of an opportunity carried out by individuals with a particular commitment in starting up a business in the university context. Scientific knowledge can be turned into the starting point of a business idea, and by extension, the birth of new a company. In the second case, possible ways of partnering with firms include cooperation agreements, consulting services, incubator facilities or assessment for start-ups. Universities' motivations to engage in such activities mainly relate to the opportunity to access to new sources of funding, and to get new ideas which can be the basis for new fundamental research. From the firms' perspective, universities offer them a broad spectrum of expertise, human capital and training. Firms also use universities' research infrastructures as a way to save money and take advantage of their expertise and setting. Similarly, firms might outsource some R\&D activities to universities because of the prohibitive costs. The benefits derived from third stream activities such as the ones described above are widely documented in the literature (Chang et al., 2009).

To cope with the challenges of adopting this third role, universities have developed new strategies and policies, and have been provided with new infrastructures to foster university-industry partnerships. Whereas the former may include the establishment of regulatory frameworks for the devolution of intellectual property rights, patents or licenses, the latter considers the creation of technology transfer offices (TTO), business incubator centres, or the establishment of science parks affiliated to universities.

\section{Data and method}

\subsection{Data}

Three outcomes are considered: patents (cutting-edge discoveries), spin-offs (new venture creation), and income from $R \& D$ contracts (how active is the university in establishing 
lucrative $R \& D$ agreements with firms). There is a widespread agreement in considering these outcomes as relevant metrics of technology transfer activities conducted at universities (Berbegal-Mirabent et al., 2012). A fourth outcome is obtained as an "OR" combination of all them.

Antecedent conditions are classified into three dimensions: human capital, financial resources, and support infrastructure. Descriptive statistics are shown in Table 1. Human capital represents the knowledge, abilities and capabilities provided by individuals. This construct is operationalised through two indicators: staff engaged in research and teaching activities (faculty members), and the technical staff from the TTO that gives specific support to technology transfer activities. Financial resources give universities the opportunity to support new research activities. This effect is particularly relevant in both knowledge creation and diffusion, as they tend to require huge investments (Landry et al., 2007). In this study we employ the budget of the TTO. Lastly, we examine the role of specific infrastructures, which are expected to positively contribute to strengthen ties with the business sector (Phan et al., 2005): business incubators and science parks.

Data come from the CRUE (Conferencia de Rectores de Universidades Españolas) and the RedOTRI (Network of Spanish Technology Transfer Offices) reports, and contains information for all Spanish public universities for the period 2004-2011.

Table 1. Descriptive statistics of the outcome and antecedent conditions

\begin{tabular}{|c|c|c|c|c|c|c|}
\hline Variables & & & Mean & Std. dev. & Min. & Max. \\
\hline \multirow{3}{*}{ Outcomes } & \multicolumn{2}{|l|}{ Patents } & 7.91 & 8.12 & 0.00 & 46.00 \\
\hline & \multicolumn{2}{|l|}{ Spin-offs } & 2.46 & 3.13 & 0.00 & 20.00 \\
\hline & \multicolumn{2}{|c|}{ R\&D contracts income* } & $9,872.24$ & $11,817.18$ & 380.22 & $8,6170.00$ \\
\hline \multirow{5}{*}{$\begin{array}{l}\text { Antecedent } \\
\text { conditions }\end{array}$} & \multirow{2}{*}{$\begin{array}{l}\text { Human } \\
\text { Resources }\end{array}$} & Faculty members & $1,267.75$ & 841.15 & 124.00 & $4,027.00$ \\
\hline & & TTO staff & 16.91 & 14.25 & 3.00 & 94.00 \\
\hline & $\begin{array}{l}\text { Financial } \\
\text { resources }\end{array}$ & TTO budget ${ }^{*}$ & 716.38 & 713.12 & 24.00 & $3,995.00$ \\
\hline & \multirow{2}{*}{$\begin{array}{l}\text { Support } \\
\text { infrastructures }\end{array}$} & Business incubator & 0.58 & 0.49 & 0.00 & 1.00 \\
\hline & & Science Park & 0.89 & 0.31 & 0.00 & 1.00 \\
\hline
\end{tabular}

* Units in thousand $€$

\subsection{Method}

Because the interest of this research is not so much which factors are necessary but which combinations of factors are sufficient to explain an outcome, this study uses qualitative comparative analysis (QCA). This method assumes complex causality and focuses on asymmetric relationships that detect configurations that are minimally necessary and/or 
sufficient for obtaining a specific outcome (Meyer et al., 1993). Configurations consist of conditions or factors that can be positive, negative, or absent.

To perform QCA, variables were transformed into a scale from 0 (full non-membership) to 1 (full membership) indicating their level of belongingness. For continuous variables we used a fuzzy-set transformation, while for dichotomous ones, crisp-set was preferred (Ragin, 2008). This process known as calibration and is reported in Table 2. In the next step, the truth table was built, followed by a reduction of the number of rows included in this table. Using Boolean algebra, the Quine-McCluskey algorithm (Quine, 1952) returned a set of combinations of causal conditions, each combination minimally sufficient to produce the outcome. Rows were reduced based on two criteria: coverage and consistency.

Table 2. Calibration values

\begin{tabular}{|c|c|c|c|c|}
\hline & & \multicolumn{3}{|c|}{ Membership threshold values ${ }^{a}$} \\
\hline \multicolumn{2}{|c|}{ Variable definition } & $\begin{array}{c}\text { Full non- } \\
\text { membership } \\
(0.05)\end{array}$ & $\begin{array}{c}\text { Crossover point } \\
(0.5)\end{array}$ & $\begin{array}{l}\text { Full membership } \\
\qquad(0.95)\end{array}$ \\
\hline \multirow{3}{*}{ Outcomes } & Patents & 1.00 & 4.00 & 17.00 \\
\hline & Spin-offs & 0.00 & 1.00 & 6.00 \\
\hline & $\mathrm{R} \& \mathrm{D}$ contracts income & $1,616.80$ & 6,611 & $18,907.60$ \\
\hline \multirow{5}{*}{$\begin{array}{l}\text { Antecedent } \\
\text { conditions }\end{array}$} & Faculty members & 422.60 & $1,046.00$ & $2,478.00$ \\
\hline & TTO staff & 5.00 & 10.00 & 34.60 \\
\hline & TTO budget & 144.00 & 485.00 & $1,706.40$ \\
\hline & Business incubator $^{b}$ & 0 & & 1 \\
\hline & Science Park ${ }^{b}$ & 0 & & 1 \\
\hline
\end{tabular}

a Observations falling in the percentile-90 to represent full set membership. Percentile-10 is the threshold value for indicating full non-membership. The crossover point is defined by the median.

${ }^{\mathrm{b}}$ Expressed in crisp-set terms.

\section{Empirical results and discussion}

We first tested whether any of the antecedent conditions was "necessary". To do this we computed the consistency scores. As any of the variables displayed values higher than 0.9 (Shneider et al., 2010), we concluded that none of the variables was a necessary condition to cause the outcome.

Table 3 shows the results for the intermediate solution. Different configurations explain the technology transfer outcomes considered, all of them exhibiting acceptable consistency indices $(\geq 0.80)$. Raw coverage values also validate our approach, being particularly high in almost all of the recipes, except for those in model $\mathrm{S}$, where values range from 0.02 to 0.35 . 
Table 3. Sufficient configurations of antecedent conditions for the different outcomes

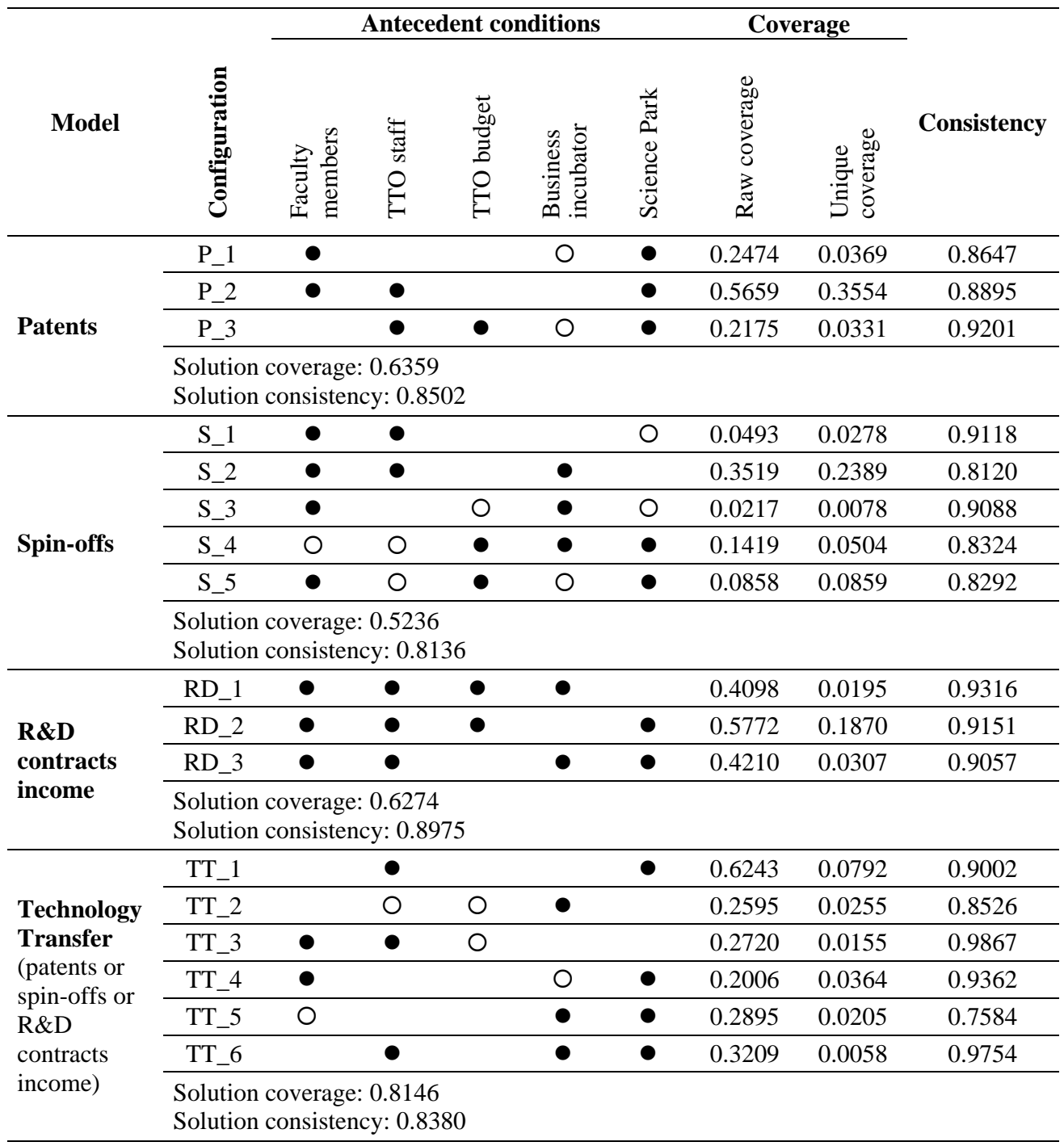

Frequency threshold $=1$.

Consistency threshold $=0.86($ Model P $),=0.83($ Model $\mathrm{S}),=0.88($ Models RD and TT).

Following Ragin and Fiss (2008) notation, black circles ("•") indicate the presence of a condition, white circles ("O") denote its absence, and blank cells represent ambiguous conditions.

Results from the models where outcomes are assessed in an individual fashion ( $\mathrm{P}, \mathrm{S}$ and $\mathrm{RD})$ suggest that there is no unique formula to produce them. In general terms, we can conclude that human capital is a highly valuable attribute, both in terms of faculty members and TTO staff. While the firsts apply their knowledge to produce cutting-edge discoveries that are sound to the industry, the latters are in charge of supporting the commercialization 
process and bring their expertise in establishing university-business collaborations. In those cases where TTO staff is scarce (S_4 and S_5, Table 3) this absence can be compensated with TTO large budgets, so that it is possible to ask for external help in this process.

Financial resources are also found to be key antecedents of technology transfer outcomes. Specifically, they are an important ingredient for R\&D contracts. Universities have to compete in a globalized market where other corporations and firms can act as R\&D providers. Therefore, marketing investments are needed in order to raise external awareness of the research conducted at universities. As for the case of spin-offs, financial support tends to come from business angels and other external agents. Yet, there are still few universities managing large amounts of seed capital.

As for the influence of support infrastructures, results suggest that science parks are useful mechanisms for bringing together businesses and research centers. Said differently, their role is relevant for patenting and the establishment of lucrative R\&D contracts. However, when it comes to create new academic ventures, the importance dilutes. On the other hand, business incubators are more relevant for spin-offs purposes.

Lastly, results from the fourth model report interesting findings. First, it is noteworthy to point out the positive effect of the science park. In four out of six configurations, a geographic enclave where firms and researchers can interact seems to play a significant role. Business incubators are another mechanism that boosts technology transfer processes. A critical mass of human capital can help overcome the absence of such advanced infrastructures. A key finding is the role of the TTO budget. Results reveal that a shortage in financial resources is not an impediment for transferring technology if there is a skilled pool of researchers that benefit from the technical expertise and help of TTO staff (configurations TT_2 and TT_3).

Following Ragin's (2008) recommendation, the two causal paths with greater raw coverage (configurations TT_1 and TT_6) deserve further attention. Both TT_1 and TT_6 are very similar. The difference relies in the role of the business incubator, which appears to be contributing to the outcome in configuration 6 , but has an imprecise role in configuration 1 .

\section{Concluding remarks}

The variety of recipes obtained suggests that there is no unique magic recipe that drives to multiple technology transfer outcomes. On the contrary, different pathways are envisioned revealing that Spanish universities can use different formulas to accomplish with the third mission. These findings reinforce the idea that universities should follow the path that best suits their strategic vision. 
To the best of the authors' knowledge, this study is one of the first examining how different technology transfer outcomes can be obtained simultaneously. The results reported here might undoubtedly bring fresh insights to both university managers and scholars in the field of technology transfer. Although measures used are reliable, future research should consider examining other combinations of technology transfer outcomes and antecedent conditions.

\section{References}

Berbegal-Mirabent, J., Lafuente, E., \& Solé, F. (2013). The pursuit of knowledge transfer activities: An efficiency analysis of Spanish universities. Journal of Business Research, 66(10), 2051-2059.

Berbegal-Mirabent, J., Sabaté, F., \& Cañabate, A. (2012). Brokering knowledge from universities to the marketplace: The role of knowledge transfer offices. Management Decision, 50(7), 1285-1307.

Chang, Y., Yang, P.Y., \& Chen, M. (2009). The determinants of academic research commercial performance: Towards an organisational ambidexterity perspective. Research Policy, 38(6), 936-946.

Landry, R., Amara, N., \& Ouimet, M. (2007). Determinants of knowledge transfer: evidence from Canadian university researchers in natural sciences and engineering. Journal of Technology Transfer, 32(6), 561-592.

Lockett, A., \& Wright, M. (2005). Resources, capabilities, risk capital and the creation of university spin-out companies. Research Policy, 34(7), 1043-1057.

Meyer, A. D., Tsui, A.S., \& Hinings, C. R. (1993). Configurational approaches to organizational analysis. Academy of Management Journal, 36(6), 1175-1195.

Phan. P.. Siegel. D. S., Wright. M. (2005). "Science parks and incubators: Observations, synthesis and future research". Journal of Business Venturing. 20(2), 165-182.

Quine, W.V. (1952). The problem of simplifying truth functions. The American Mathematical Monthly, 59(8), 521-531.

Ragin, C. C. (2008). Redesigning social inquiry: Fuzzy sets and beyond. Chicago: University of Chicago Press.

Ragin, C. C., \& Fiss, P. (2008). Net effects analysis versus configurational analysis: An empirical demonstration. In C.C. Ragin (ed.): Redesigning Social Inquiry: Fuzzy Sets and Beyond (pp. 190-212). Chicago, IL: University of Chicago Press.

Schneider, M. R., Schulze-Bentrop, C., \& Paunescu, M. (2010). Mapping the institutional capital of high-tech firms: A fuzzy-set analysis of capitalist variety and export performance. Journal of International Business Studies, 41(2), 246-266.

Shattock, M. (2009). Entrepreneurialism in universities and the knowledge economy. Maidenhead: Society for Research into Higher Education and Open University Press. 